MODELING, IDENTIFICATION AND CONTROL, 1996, VOL. 17, NO. 4, 279-295

doi:10.4173/mic.1996.4.3

\title{
Model-Based Optimizing Control of a Water-to-Water Heat Pump Unit
}

\author{
MORTEN CHRISTIAN SVENSSON $\dagger$
}

Keywords: Dynamic optimization; heat pumps; nonlinear programming

This paper outlines the basic principles of on-line model-based steady-state optimizing control of continuous processes, and illustrates how this control approach can be used to optimize the operating conditions of heat pumps.

The multilayer approach of hierarchical control theory is used to synthesise the control structure, and the control objectives are decomposed into regulatory and optimizing control tasks. The optimization problem in the optimizing control system is solved within an "infeasible path" nonlinear programming approach, where the performance criterion, the adaptive steady-state process model, and the operational feasibility constraints are solved simultaneously using a sequential quadratic programming (SQP) algorithm.

An on-line model-based optimizing control algorithm is implemented on a personal computer and used to minimize the energy consumption of an experimental water-to-water electric-motor driven heat pump unit. During a period of steady process operation, process data is gathered and used to update parameters in the steady-state heat pump model. The updated process model is then used to calculate new set-points for the regulatory control system that minimize the total electric power input to the heat pump unit while not violating the operational feasibility constraints.

The various energy losses in the heat pump unit are shown to verify the ability of the optimizing control system to conserve energy.

\section{Introduction}

Increased energy and raw material cost, and increased process integration have highlighted the need for extended use of advanced process control. As computers decrease in cost while increasing in memory capacity and calculation speed, previous limitations to perform on-line process optimization with rigorous process models and nonlinear programming techniques are vanishing. The application of advanced process control may result in (Latour 1979):

- Reduced energy consumption and operating cost.

- Improved product quality.

- Increased capacity of equipment.

- Less maintenance cost.

- Tighter, and lower cost process design.

On-line optimization schemes are of two basic types: (i) direct-search or model-free; (ii) indirect, or model-based. Model-based techniques offer considerable advantages over model-free methods provided a suitable process model is available. When no model is used, experiments must be performed directly on the process in order to determine the optimum operating conditions. A comprehensive review of the state of

Received 25 September 1995.

$\dagger$ Department of Electrical Engineering, Høgsholen i Sør-Trøndelag, Trondheim, NorwaySchool of Engineering and Food Science. 
the art in optimizing control is provided in an article by Arkun and Stephanopoulos (1980).

Predictive models can be divided into empirical or regression models and physical process models. Empirical models take no account of the physical structure of the process, but are generally simple in form and easy to solve. Physical process models, which are based on conservation of mass, energy and momentum, are more likely to yield an accurate process description but are often more difficult to solve. Few models are exact representations of the process, so if the predicted optimum operating conditions are to approach the actual optimum process operating conditions, the model parameters need to be updated on the basis of recent measurements. A typical on-line model-based optimizing control scheme involves three phases in each optimization cycle (Jackson et al. 1980):

1. Model identification. In the identification phase model parameters are estimated or updated in order to minimize the mismatch between the model and process.

2. Optimization. In the optimization phase the optimum process operating conditions are predicted on the basis of the updated process model.

3. Control. In the third phase the new optimum set-points are implemented.

The accuracy of the model prediction determines the number of cycles to be taken before the true optimum is found. Jackson et al. (1980) discuss the relation between model complexity and their ability to predict optimum operating conditions.

The objective of this paper is to outline the basic principles of on-line model-based steady-state optimizing control of continuous processes. The presented control structure represents a systematic procedure for achieving a well-defined economic performance optimum, rather than temporary or ad hoc solutions to specific situations. During a period of steady process operation, process data is gathered and used to update parameters in a steady-state process model. The model is then used to calculate a set of new set-points for the regulatory control system that optimize the process performance while not violating the equipment and operational constraints. The on-line optimizing control approach is illustrated with an example from an experimental water-to-water heat pump unit.

\section{Multilayer decomposition of control tasks}

The overall control objective during process operation is to optimize an economic measure of the operation (minimize operating cost, maximize profit, etc.), while at the same time satisfying certain equality or inequality constraints such as production specifications, safety considerations, operational requirements, environmental regulations, etc. To assure a practical implementation of the resulting control system, Lefkowitz (1966) proposes a decomposition of the control tasks and a partition of the process into sub-processes. The control tasks are decomposed vertically into a number of simpler control functions forming a hierarchy of control activities. The process may further be divided into a number of simpler sub-processes, each of which is controlled according to a local criterion, with their action coordinated by an additional supremal unit.

The multilayer hierarchy structure is a vertical decomposition of the control tasks and is motivated by the presence of disturbances with different frequencies and economic impacts entering the process. Figure 1 shows a 4-layer decomposition consisting of regulation, optimization, adaption and self-organization. The first layer takes care of the regulatory control tasks of keeping the process variables at given 


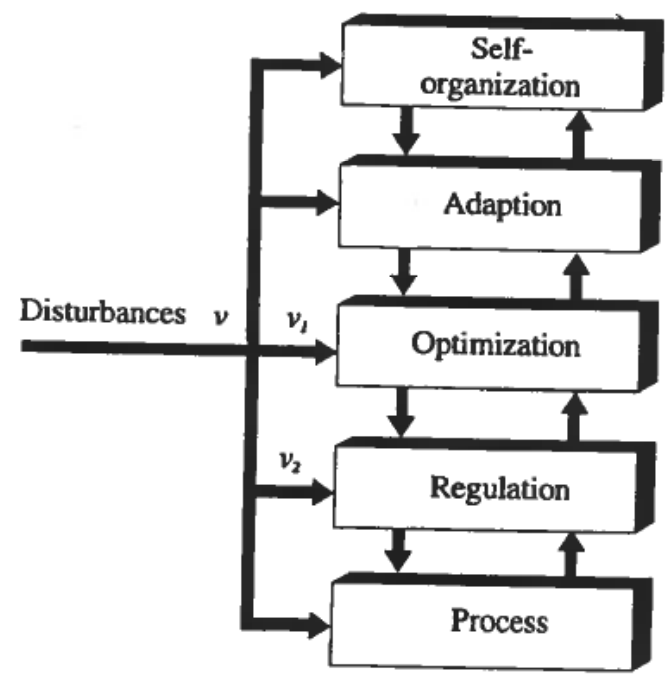

Figure 1. Multilayer decomposition of the control tasks (Lefkowitz 1966).

set-points or within certain bounds, despite uncontrolled disturbances. The second layer takes care of the optimizing control tasks, where the objective is to determine optimum operating conditions for the process based on an appropriate performance criterion and a mathematical process model. The purpose of the adaptive function in the third layer is to compensate for model-induced errors by adjusting the model parameters or controller parameters associated with the control algorithms of the first and second layer. The self-organization function in the fourth layer defines the structures of the lower-level controllers through assumptions concerning the system and its environment (abnormal operation, criterion for sub-optimum performance, frequency of second and third layer control action, etc.).

The control problem associated with continuous processes, as distinct from batch processes, is focused on in this paper. The following assumptions are made (Lefkowitz 1966):

- The process is designed for steady-state operation.

- The process is subjected to a variety of disturbances; however, the regulatory control system is capable of maintaining the process reasonably close to the specified steady-state operating point.

- The average frequency, with which the optimizing controller calls for a new steady-state operating point, is low relative to the response speed of the process, i.e. the system is in transition from one steady-state to another only a small fraction of the time.

Morari et al. (1980) divided the process disturbances $v$ in two categories:

1. Non-stationary "slow varying" disturbances $v_{1}$ which are candidates for optimizing control action.

2. "Fast varying" disturbances $v_{2}$, which are irrelevant for the long term optimization of the process.

The regulatory control system is used to suppress the influence of the "fast varying" disturbances. A classification of the "slow varying" disturbances based on their 
economic impact on the overall performance criterion will define the need for optimizing control actions.

As a result of the assumptions mentioned above, the dynamics of the process can be ignored in the optimization layer of the control hierarchy. The operating conditions of the process are characterized by pseudo-steady-state conditions, and the general steady-state optimizing control problem can be fomulated as:

$$
\min _{u} \Phi(x, u, v)
$$

subject to

$$
\begin{aligned}
& f(x, u, v, \theta)=0 \\
& h(x, u, v, \theta)=0 \\
& g(x, u, v, \theta) \leq 0
\end{aligned}
$$

where $\boldsymbol{x}$ is the vector of state variables, $\boldsymbol{u}$ is the vector of manipulated variables, $v$ is the vector of disturbances, and $\boldsymbol{\theta}$ is the vector of model parameters. $\boldsymbol{\Phi}$ is the performance criterion, $\boldsymbol{f}$ is the vector of model equations, $\boldsymbol{h}$ is the vector of operational equality constraints, and $g$ is the vector of operational inequality constraints.

\section{Application to a heat pump unit}

A heat pump is a system which extracts heat from a heat source and transfers the heat to a higher temperature level where it can be used beneficially. The heat pump thermodynamic cycle is identical with the modified Carnot cycle used in refrigeration, but the term heat pump is reserved for systems that provide heating for beneficial purposes, rather than those which remove heat for cooling only. Heat pumps play an important role in energy conservation, both in industrial and domestic installations. According to the second law of thermodynamics, heat cannot be transferred from a low to a high temperature without the addition of higher level energy like electricity or mechanical work. The higher level energy requirements may be reduced significantly through improved operation. This is achieved not only through optimum heat pump design, but requires in addition a control system which is able to find and maintain the economically optimum operating conditions of the heat pump. Improved strategies for heat pump control offer a viable means for significant energy savings as compared to existing control techniques.

Zimmer (1976) and Cho (1982) use empirical models to minimize the operating cost of a refrigeration system. The model is adapted to the process using a factorial, experimental design. They use a Nelder-Mead Simplex method for function minimization. Cho (1982) modifies the method to handle operational constraints through the use of penalty functions. Kaya and Sommer (1985) present a multilevel control and optimization scheme of a chiller system. The scheme provides supervisory adjustments of set-points, optimum load allocation of chillers and pumps based on an incremental cost strategy, and coordination of conflicting goals of subsystems. Olson et al. (1990) present a mathematical programming approach to determine which available chiller plant equipment to use to meet a cooling load as well as the best operating temperatures for the water flows throughout the system. They use a heuristic approach for handling the integer variables and solve a series of continuous problems using sequential quadratic programming. MacArthur et al. (1988) present an optimal comfort control concept for variable-speed heat pumps. The control objective is to 


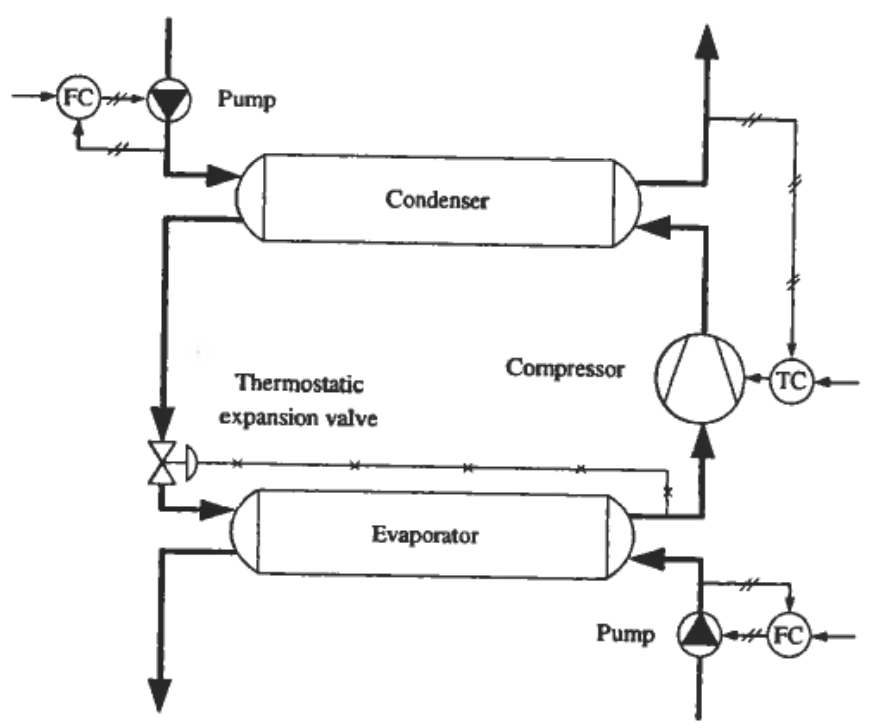

Figure 2. Flow chart of the heat pump unit.

maximize system performance while simultaneously satisfying comfort conditions. They use a multi-dimensional steady-state direct-search technique to evaluate the system Jacobian. Braun et al. (1989) present two methodologies for determining the optimum control settings for chilled water systems. They first present a componentbased nonlinear optimization algorithm as a simulation tool for investigating optimum system performance. Results of this algorithm led to the development of system-based methodology for near-optimal control that is simple enough for on-line implementation.

In the following case studies in this paper, the model-based steady-state optimizing control approach is used on-line to optimize the operating conditions of an experimental water-to-water electric-motor driven heat pump unit. Figure 2 shows the flow chart of the heat pump unit, where the main components are a semi-hermetic variable-speed reciprocating compressor, a horizontal shell-and-tube condenser, two thermostatic expansion valves (only one drawn in the figure), a dry expansion shell-and-tube evaporator, and two variable-speed centrifugal pumps. The refrigerant is R-22. Not shown in the flow chart is two water tanks, whose purpose is to provide constant inlet water temperatures to the evaporator and condenser. The heat pump unit measurements, manipulated variables, and disturbances are given in Table 1, Table 2, and Table 3.

The specific configuration of the experimental heat pump unit consisting of a constant condenser water inlet temperature, and the absence of an external system with its exergy and temperature requirements, enforces some assumptions which are specific to this experimental set-up:

- The heat pump unit load specification is assumed to be the exergy requirement of the non-existent external system. The temperature requirement is not considered.

- The condenser water outlet temperature is considered as the controlled variable. 
Table 1. Heat pump unit measurements

\begin{tabular}{llll}
\hline Variable name & Symbol & $\begin{array}{l}\text { Variable } \\
\text { number }\end{array}$ & Units \\
\hline Compressor unit electric power input & $\dot{P}_{\mathrm{com}}$ & $y_{1}$ & $\mathrm{~kW}$ \\
Compressor discharge temperature & $T_{\mathrm{dis}}$ & $y_{2}$ & ${ }^{\circ} \mathrm{C}$ \\
Condenser water outlet temperature & $T_{\mathrm{sc}, \mathrm{out}}$ & $y_{3}$ & ${ }^{\circ} \mathrm{C}$ \\
Condenser water volume flow rate & $\dot{V}_{\mathrm{sc}}$ & $y_{4}$ & $\mathrm{~m}^{3} / \mathrm{s}$ \\
Evaporator water volume flow rate & $\dot{V}_{\mathrm{se}}$ & $y_{5}$ & $\mathrm{~m}^{3} / \mathrm{s}$ \\
Evaporator water outlet temperature & $T_{\mathrm{se}, \text { out }}$ & $y_{6}$ & ${ }^{\circ} \mathrm{C}$ \\
Evaporator refrigerant outlet pressure & $p_{\mathrm{e}}$ & $y_{7}$ & $\mathrm{bar}$ \\
Condenser refrigerant outlet pressure & $p_{\mathrm{c}}$ & $y_{8}$ & $\mathrm{bar}$ \\
Compressor suction line temperature & $T_{\mathrm{suc}}$ & $y_{9}$ & ${ }^{\circ} \mathrm{C}$ \\
Condenser refrigerant outlet temperature & $T_{\mathrm{liq}}$ & $y_{10}$ & ${ }^{\circ} \mathrm{C}$ \\
Evaporator water inlet temperature & $T_{\mathrm{se}, \mathrm{in}}$ & $y_{11}$ & ${ }^{\circ} \mathrm{C}$ \\
Evaporator water pump electric power input & $\dot{P}_{\mathrm{pe}}$ & $y_{12}$ & $\mathrm{~kW}$ \\
Condenser water pump electric power input & $\dot{P}_{\mathrm{pc}}$ & $y_{13}$ & $\mathrm{~kW}$ \\
Condenser water inlet temperature & $T_{\mathrm{sc}, \mathrm{in}}$ & $y_{14}$ & ${ }^{\circ} \mathrm{C}$ \\
\hline
\end{tabular}

Table 2. Heat pump unit manipulated variables

\begin{tabular}{ll}
\hline Variable name & Units \\
\hline Evaporator water volume flow rate & $\mathrm{m}^{3} / \mathrm{s}$ \\
Compressor refrigerant volume flow rate & $\mathrm{m}^{3} / \mathrm{s}$ \\
Condenser water volume flow rate & $\mathrm{m}^{3 / s}$ \\
Evaporator refrigerant inlet volume flow rates (2) & $\mathrm{m}^{3} / \mathrm{s}$ \\
\hline
\end{tabular}

Table 3. Heat pump unit disturbances

\begin{tabular}{lll}
\hline Variable name & Symbol & Units \\
\hline Evaporator water inlet temperature & $T_{\text {se,in }}$ & ${ }^{\circ} \mathrm{C}$ \\
Condenser water inlet temperature & $T_{\text {sc,in }}$ & ${ }^{\circ} \mathrm{C}$ \\
Exergy requirement & $\dot{E}_{\mathrm{hp}}$ & $\mathrm{kW}$ \\
\hline
\end{tabular}

\subsection{Control objectives}

The control objectives for the experimental heat pump unit are typical for heat pump applications:

- Maintain process variables at desired values.

- Keep process operating conditions within equipment and operational constraints.

- Optimize the economic performance of the process.

The controlled variables of the experimental heat pump unit are the condenser water outlet temperature, the water flow rates through the evaporator and condenser, and the degree of superheat in the suction line. The main objective of the regulatory control system is to maintain these controlled variables at their set-points. The regulatory control system consists of one temperature controller (TC), two flow controllers (FC), and two degree of superheat controllers (thermostatic expansion valves). The final control elements are the variable-speed compressor, the two variable-speed water pumps, and the two expansion valves. 
Optimum heat pump performance occurs at the minimum degree of superheat at the evaporator outlet, which is due to the higher two-phase heat-transfer coefficient compared to the single-phase heat-transfer coefficient (Tassou et al. 1993, Galloway et al. 1991). It is assumed that the degree of superheat controllers maintain the degree of superheat at the evaporator outlet at this minimum.

The equipment and operational constraints of the heat pump unit are given in Table 4, and are based on the following considerations:

- Protection against air leakage into the evaporator and compressor by keeping the low refrigerant pressure above atmospheric pressure. A lower limit on the suction pressure also prevents overheating of the hermetic motor.

- Protection against freezing of water inside the evaporator shell.

- Protection of the compressor against liquid entering from the evaporator through the suction line. This constraint is implicitly taken care of by the two degree of superheat controllers.

- Protection of the hermetic compressor motor and pump motors against overload.

- Protection against lubricant and refrigeration breakdown at the discharge side of the compressor.

- Speed reduction is limited $(25 \mathrm{~Hz})$ to prevent compressor lubrication, oil return, and motor overheating problems. The upper limit of compressor speed $(75 \mathrm{~Hz})$ is set according to degradation of compressor valves and bearings performance. These constraints are not included in the optimizing control system, but are implemented in the regulatory control system.

- High pressure protection of the condenser and compressor crankcase and housing.

The main objective of the optimizing control system is to find the optimum set-points for the temperature controller and the two flow controllers in the regulatory control system that minimize the total exergy input (total electric power input) to the heat pump unit. The solution to this optimization problem must satisfy the heat pump unit load specification, and not violate the equipment and operational constraints given in Table 4.

Table 4. Heat pump unit equipment and operational constraints

\begin{tabular}{llcc}
\hline & & \multicolumn{2}{c}{ Normal operating limits } \\
\cline { 3 - 4 } Variable name & Symbol & Low limit & High limit \\
\hline Evaporator saturation temperature & $T_{\mathrm{e}}^{\text {sat }}$ & $-40 \cdot 0^{\circ} \mathrm{C}$ & none \\
Evaporator water outlet temperature & $T_{\text {se.out }}$ & $2 \cdot 0^{\circ} \mathrm{C}$ & none \\
Evaporator pump electric power input & $\dot{P}_{\mathrm{pe}}$ & none & $2 \cdot 2 \mathrm{~kW}$ \\
Compressor unit electric power input & $\dot{P}_{\text {com }}$ & none & $20 \cdot 5 \mathrm{~kW}$ \\
Compressor discharge temperature & $T_{\mathrm{dis}}$ & none & $105 \cdot 0^{\circ} \mathrm{C}$ \\
Condenser saturation temperature & $T_{\mathrm{c}}^{\mathrm{sal}}$ & none & $60 \cdot 0^{\circ} \mathrm{C}$ \\
Condenser pump electric power input & $\dot{P}_{\mathrm{pc}}$ & none & $2 \cdot 2 \mathrm{~kW}$ \\
\hline
\end{tabular}

\subsection{On-line optimization}

In the optimization phase the heat pump unit performance criterion $\boldsymbol{\Phi}$ is minimized with respect to the freed variables $T_{\mathrm{sc}, \text { out }}, \dot{V}_{\mathrm{se}}$, and $\dot{V}_{\mathrm{sc}}$. The updated parameter vector $\boldsymbol{\theta}$, and the mean values of the disturbances calculated in the most recent time horizon, are 
held constant in the optimization phase. The optimization problem, which consists of 8 independent variables (Table 5), 6 equality constraints and 7 inequality constraints, is formulated as:

$$
\min \boldsymbol{\Phi}=\hat{\dot{P}}_{\mathrm{com}}+\hat{\dot{P}}_{\mathrm{pe}}+\hat{\dot{P}}_{\mathrm{pc}}
$$

subject to the updated model equations:

$$
\begin{aligned}
& f_{1}=\hat{\dot{V}}_{\mathrm{sc}} \hat{\rho}_{\mathrm{sc}} \hat{c}_{\mathrm{p}, \mathrm{sc}}\left(\hat{T}_{\mathrm{sc}, \mathrm{out}}-\hat{T}_{\mathrm{sc}, \mathrm{in}}\right)-\theta_{1} \hat{\dot{P}}_{\mathrm{com}}\left(\hat{h}_{\mathrm{dis}}-\hat{h}_{\mathrm{liq}}\right) /\left(\hat{h}_{\mathrm{dis}}-\hat{h}_{\mathrm{suc}}\right) \\
& f_{2}=\hat{\hat{V}}_{\mathrm{se}} \hat{\rho}_{\mathrm{se}} \hat{c}_{\mathrm{p}, \mathrm{se}}\left(\hat{T}_{\mathrm{se}, \mathrm{in}}-\hat{T}_{\mathrm{se}, \mathrm{out}}\right)-\theta_{2} \hat{\hat{P}}_{\mathrm{com}}\left(\hat{h}_{\mathrm{suc}}-\hat{h}_{\mathrm{liq}}\right) /\left(\hat{h}_{\mathrm{dis}}-\hat{h}_{\mathrm{suc}}\right) \\
& f_{3}=\left(\hat{T}_{\mathrm{c}}^{\mathrm{sat}}-\hat{T}_{\mathrm{sc}, \mathrm{in}}\right)-\left(\hat{T}_{\mathrm{c}}^{\mathrm{sat}}-\hat{T}_{\mathrm{sc}, \mathrm{out}}\right) \exp \left[A_{\mathrm{sc}} / \hat{\dot{V}}_{\mathrm{sc}} \hat{\rho}_{\mathrm{sc}} \hat{c}_{\mathrm{p}, \mathrm{sc}}\left(\theta_{3}+k_{1} \hat{\dot{V}}_{\mathrm{sc}}^{-0.8}\right)\right] \\
& f_{4}=\left(\hat{T}_{\mathrm{se}, \mathrm{in}}-\hat{T}_{\mathrm{e}}^{\mathrm{sat}}\right)-\left(\hat{T}_{\mathrm{sc}, \mathrm{out}}-\hat{T}_{\mathrm{e}}^{\mathrm{sat}}\right) \exp \left[A_{\mathrm{se}} / \hat{V}_{\mathrm{se}} \hat{\rho}_{\mathrm{se}} \hat{c}_{\mathrm{p}, \mathrm{se}}\left(\theta_{4}+\theta_{5} \hat{\dot{V}}_{\mathrm{se}}^{-0.6}\right)\right] \\
& f_{5}=\left(\hat{h}_{\mathrm{is}}-\hat{h}_{\mathrm{suc}}\right)-\theta_{6}\left(\hat{h}_{\mathrm{dis}}-\hat{h}_{\mathrm{suc}}\right)
\end{aligned}
$$

subject to the operational equality constraint:

$$
h_{1}=\hat{\dot{V}}_{\mathrm{sc}} \hat{\rho}_{\mathrm{sc}} \hat{\boldsymbol{c}}_{\mathrm{p}, \mathrm{sc}}\left\{\left(\hat{T}_{\mathrm{sc}, \text { out }}-\hat{T}_{\mathrm{sc}, \mathrm{in}}\right)-\mathscr{T}_{\mathrm{ref}} \ln \left[\hat{\mathscr{T}}_{\mathrm{sc}, \mathrm{out}} / \hat{\mathscr{T}}_{\mathrm{sc}, \mathrm{in}}\right]\right\}-\theta_{7}
$$

subject to the operational inequality constraints:

$$
\begin{aligned}
& g_{1}=-40 \cdot 0-\hat{T}_{\mathrm{e}}^{\mathrm{sat}} \\
& g_{2}=\hat{P}_{\mathrm{pe}}-2 \cdot 2 \\
& g_{3}=2 \cdot 0-\hat{T}_{\mathrm{se}, \mathrm{out}} \\
& g_{4}=\hat{T}_{\mathrm{dis}}-105 \cdot 0 \\
& g_{5}=\hat{\hat{P}}_{\mathrm{com}}-20 \cdot 5 \\
& g_{6}=\hat{T}_{\mathrm{c}}^{\mathrm{sat}}-60 \cdot 0 \\
& g_{7}=\hat{P}_{\mathrm{pc}}-2 \cdot 2
\end{aligned}
$$

where

$$
\hat{\dot{P}}_{\mathrm{pc}}=\theta_{8} \hat{\dot{V}}_{\mathrm{sc}}^{3 \cdot 0} \quad \hat{\dot{P}}_{\mathrm{pe}}=\theta_{9} \hat{\dot{V}}_{\mathrm{se}}^{3 \cdot 0} \quad \text { and } \quad \mathscr{T}_{\text {ref }}=273 \cdot 15
$$

The notation ${ }^{\wedge}$ is used to distinguish between predicted and measured variables. The thermodynamic property equations are regressed from data generated by rigorous thermodynamic routines. The mean values of the measurements in the last time horizon are used as starting values for the independent variables.

Table 5. Independent variables in the heat pump unit optimization problem

\begin{tabular}{llll}
\hline Variable name & Symbol & $\begin{array}{l}\text { Variable } \\
\text { number }\end{array}$ & Units \\
\hline Compressor unit electric power input & $\hat{\hat{P}}_{\text {com }}$ & $x_{1}$ & $\mathrm{~kW}$ \\
Compressor discharge temperature & $\hat{T}_{\text {dis }}$ & $x_{2}$ & ${ }^{\circ} \mathrm{C}$ \\
Condenser water outlet temperature & $\hat{T}_{\mathrm{scout}}$ & $x_{3}$ & ${ }^{\circ} \mathrm{C}$ \\
Condenser water volume flow rate & $\hat{\hat{V}}_{\mathrm{sc}}$ & $x_{4}$ & $\mathrm{~m}^{3} / \mathrm{s}$ \\
Evaporator water volume flow rate & $\hat{\hat{V}}_{\mathrm{sc}}$ & $x_{5}$ & $\mathrm{~m}^{3} / \mathrm{s}$ \\
Evaporator water outlet temperature & $\hat{T}_{\mathrm{se}, \text { out }}$ & $x_{6}$ & ${ }^{\circ} \mathrm{C}$ \\
Evaporator saturation temperature & $\hat{T}_{\mathrm{e}}^{\text {sat }}$ & $x_{7}$ & ${ }^{\circ} \mathrm{C}$ \\
Condenser saturation temperature & $\hat{T}_{\mathrm{c}}^{\text {sat }}$ & $x_{8}$ & ${ }^{\circ} \mathrm{C}$ \\
\hline
\end{tabular}


The equality constraints $f_{1}$ to $f_{5}$ represent the adaptive heat pump unit model. The refrigerant mass flow rate is eliminated in the model equations by substitution of the compressor unit energy equation, and the log terms in the logarithmic mean temperature difference expressions are removed by applying exponential transformations. The equality constraint $h_{1}$ represents the load specification, i.e. the exergy requirement, and the inequality constraints $g_{1}$ to $g_{7}$ ensure an operational feasible solution, i.e. not rejecting the equipment and operational constraints of the heat pump unit.

The optimization problem is solved within an "infeasible path" nonlinear programming approach, where the performance criterion, the model equations, and the operational feasibility constraints are solved simultaneously using a sequential quadratic programming algorithm (Schittkowski 1985, Edgar et al. 1989).

\subsection{On-line steady-state identification}

In the identification phase, the model parameters $\boldsymbol{\theta}$ are updated within a moving-horizon approach by inverting the steady-state heat pump unit model. In the moving-horizon approach the measurements are treated like a batch for a given time horizon. This time horizon is moving such that it always contains the most recent measurements. The identification algorithm is subjected to steady-state operating conditions, which necessitates a criterion for the verification of steady-state. In this paper a criterion based on a statistical test of the measurements in the last time horizon is used. The time horizon is divided in 3 equal time intervals and the mean values of the measurements are calculated in each interval. The hypothesis of steady-state operating conditions is rejected if for any measurment $i$ :

$$
\max _{j=1, \ldots, 3}\left\{\bar{y}_{i j}\right\}-\min _{j=1, \ldots, 3}\left\{\bar{y}_{i j}\right\} \geq k_{\alpha} \sigma_{i}
$$

where $\bar{y}_{i j}$ is the mean value of the $i$ th measurement in the $j$ th time interval, $k_{\alpha}$ is the level of significance, and $\sigma_{i}$ is the standard deviation of the mean value of the $i$ th measurement.

If the steady-state hypothesis is not rejected the model parameters are calculated from the mean values of the measurements in the last time horizon inserted in the following inverted model equations:

$$
\begin{aligned}
& \theta_{1}=\dot{V}_{\mathrm{sc}} \rho_{\mathrm{sc}} c_{\mathrm{p}, \mathrm{sc}}\left(T_{\mathrm{sc}, \text { out }}-T_{\mathrm{sc}, \mathrm{in}}\right)\left(h_{\mathrm{dis}}-h_{\mathrm{suc}}\right) / \dot{P}_{\mathrm{com}}\left(h_{\mathrm{dis}}-h_{\text {liq }}\right) \\
& \theta_{2}=\dot{V}_{\text {se }} \rho_{\text {se }} c_{\text {p.se }}\left(T_{\text {se.in }}-T_{\text {se }, \text { out }}\right)\left(h_{\text {dis }}-h_{\text {suc }}\right) / \dot{P}_{\text {com }}\left(h_{\text {suc }}-h_{\text {liq }}\right) \\
& \theta_{3}=A_{\mathrm{sc}} / \dot{V}_{\mathrm{sc}} \rho_{\mathrm{sc}} c_{\mathrm{p}, \mathrm{sc}} \ln \left[\left(T_{\mathrm{c}}^{\mathrm{sat}}-T_{\mathrm{sc}, \text { in }}\right) /\left(T_{\mathrm{c}}^{\mathrm{sat}}-T_{\mathrm{sc}, \text { out }}\right)\right]-k_{1} \dot{V}_{\mathrm{sc}}^{-0.8} \\
& \theta_{4}=k_{2}\left[\left(\dot{V}_{\mathrm{se}} \rho_{\mathrm{se}} c_{\mathrm{p}, \mathrm{se}}\left(T_{\mathrm{se}, \mathrm{in}}-T_{\mathrm{se}, \mathrm{out}}\right)\right)^{2} /\left(h_{\mathrm{suc}}-h_{\mathrm{liq}}\right)\right]^{-0.4} \\
& \theta_{5}=\dot{V}_{\mathrm{se}}^{0.6}\left(A_{\mathrm{se}} / \dot{V}_{\mathrm{se}} \rho_{\mathrm{se}} c_{\mathrm{p}, \mathrm{se}} \ln \left[\left(T_{\mathrm{se}, \text { in }}-T_{\mathrm{e}}^{\mathrm{sat}}\right) /\left(T_{\mathrm{se}, \text { out }}-T_{\mathrm{e}}^{\mathrm{sat}}\right)\right]-\theta_{4}\right) \\
& \theta_{6}=\left(h_{\text {is }}-h_{\text {suc }}\right) /\left(h_{\text {dis }}-h_{\text {suc }}\right) \\
& \theta_{7}=\dot{V}_{\mathrm{sc}} \rho_{\mathrm{sc}} c_{\mathrm{p}, \mathrm{sc}}\left\{\left(T_{\mathrm{sc}, \text { out }}-T_{\mathrm{sc}, \mathrm{in}}\right)-\mathscr{T}_{\mathrm{ref}} \ln \left[\mathscr{T}_{\mathrm{sc}, \mathrm{out}} / \mathscr{T}_{\mathrm{sc}, \mathrm{in}}\right]\right\} \\
& \theta_{8}=\dot{P}_{\mathrm{pc}} / \dot{V}_{\mathrm{sc}}^{3.0} \\
& \theta_{9}=\dot{P}_{\mathrm{pe}} / \dot{V}_{\mathrm{se}}^{3.0} \\
& \theta_{10}=T_{\text {suc }}-T_{\mathrm{e}}^{\text {sat }} \\
& \theta_{11}=T_{\mathrm{c}}^{\mathrm{sat}}-T_{\text {liq }}
\end{aligned}
$$


where

$$
k_{1}=1.166 \times 10^{-3} \text { and } k_{2}=4 \cdot 164
$$

The constants $k_{1}$ and $k_{2}$ are calculated from geometrical and thermo-physical data.

\subsection{Results and discussion}

The heat pump unit was allowed to come to steady-state at an arbitrarily chosen base case point, from which the incremental predictions were made. A limit of two optimization cycles was set during each experiment. The time horizon was set to $600 \mathrm{~s}$ with no overlap between two subsequent time horizons. The sampling time was approximately $5 \mathrm{~s}$. Instability in the degree of superheat control loops demanded a relaxation of the steady-state operating condition criterion in equation 20.

\section{Case I}

The initial set-points for the temperature controller, and the evaporator and condenser flow controllers were set at $47.4^{\circ} \mathrm{C}, 3.0 \times 10^{-3} \mathrm{~m}^{3} / \mathrm{s}$, and $3.0 \times 10^{-3} \mathrm{~m}^{3} / \mathrm{s}$ respectively. The evaporator and condenser water inlet temperatures were $9.5^{\circ} \mathrm{C}$ and $43 \cdot 5^{\circ} \mathrm{C}$.

Table 6 shows the mean values of the measurements $y$, the estimated parameters $\boldsymbol{\theta}$, and the optimum independent variables $\boldsymbol{x}^{\text {opt }}$ during two optimization cycles. The optimizing controller seemed to converge to the optimum during the two cycles. 8 iterations and a computation time of approximately $20 \mathrm{CPU}$ seconds were used to find the solution of the optimization problem in the first cycle.

The calculated optimum set-points for the temperature controller, and the evaporator and condenser flow controller were $50.93^{\circ} \mathrm{C}, 1.60 \times 10^{-3} \mathrm{~m}^{3} / \mathrm{s}$, and $1.52 \times 10^{-3} \mathrm{~m}^{3} / \mathrm{s}$ respectively. The power input to the evaporator water pump decreased from 1.72 to $0.41 \mathrm{~kW}$. The evaporator pressure and the evaporator water outlet temperature decreased from 5.24 to 5.02 bar, and 6.69 to $4.42^{\circ} \mathrm{C}$ respectively. The power input to the condenser water pump decreased from 1.26 to $0.30 \mathrm{~kW}$. The condenser pressure and the condenser water outlet temperature increased from 18.73 to 20.45 bar, and 47.38 to $50.93^{\circ} \mathrm{C}$ respectively. The power input to the compressor unit increased from $14.18 \mathrm{~kW}$ to $14.96 \mathrm{~kW}$. Due to the optimum allocation of the power input to the compressor unit and the two water pumps, the total electrical power input decreased from $17.16 \mathrm{~kW}$ to $15.67 \mathrm{~kW}$, i.e. a reduction of $8.7 \%$.

Figure 3 shows the distribution of the various exergy losses in the heat pump unit in the base case point, after the first optimization cycle, and after the second optimization cycle. The exergy losses in the two water pumps decreased due to the reduced power input to the pumps. The exergy losses in the compressor unit and expansion valves increased due to the increased temperature lift $\left(T_{\mathrm{c}}^{\text {sat }}-T_{\mathrm{e}}^{\text {sat }}\right)$. The reduced water flow rates through the evaporator and condenser resulted in a poorer utilization of the heat exchanger areas. The temperature profile mismatch increased, and the reduced heat-transfer coefficients on the water sides resulted in an increase in the required temperature differences in the heat exchangers. In spite of this the heat pump unit exergy losses decreased from 11.7 to $10.0 \mathrm{~kW}$. The heat pump unit exergetic efficiency increased from $\zeta_{e x}=0.408$ to $\zeta_{e x}=0.446$, i.e. an increase of $9.3 \%$.

Figure 4 shows the contour and constraint diagram for the second cycle optimization problem. The axis of the diagram are the water flow rates in the evaporator and condenser. Figure 4 shows that the feasible region of operation was constrained by the 


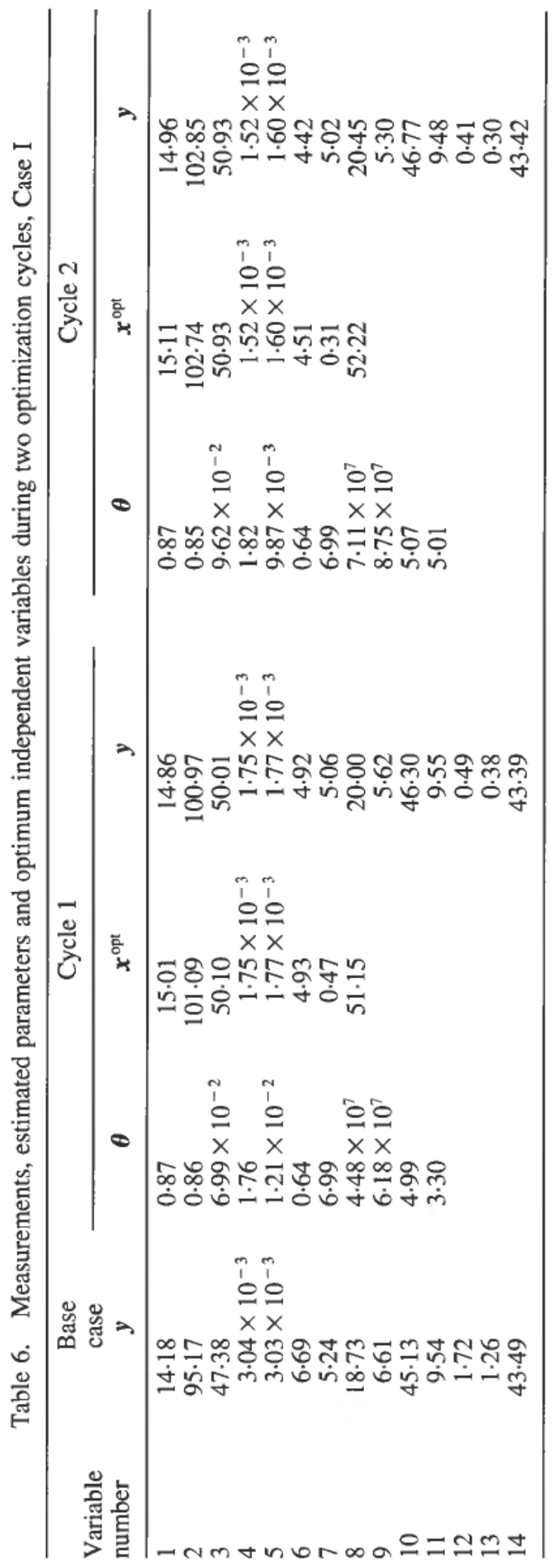




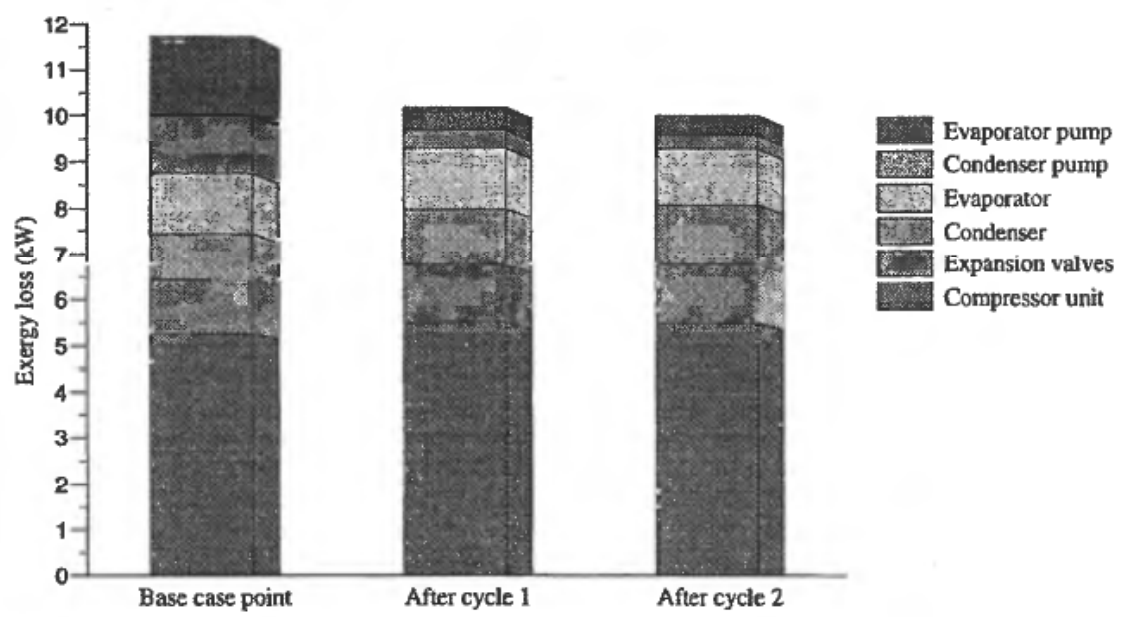

Figure 3. The distribution of the various exergy losses in the heat pump unit. Case I.

capacity limits of the pumps ( $g_{2}$ and $\left.g_{7}\right)$, the water freezing limit in the evaporator $\left(g_{3}\right)$, and the compressor discharge temperature high limit $\left(g_{4}\right)$. The calculated optimum power input to the heat pump unit was $15.6 \mathrm{~kW}$, and no inequality constraints were active at the optimum. Any change in the heat pump unit disturbances may result in constraint violation, and the next case study presents an example where the optimum operating conditions of the heat pump unit lie at the intersection of two inequality constraints.

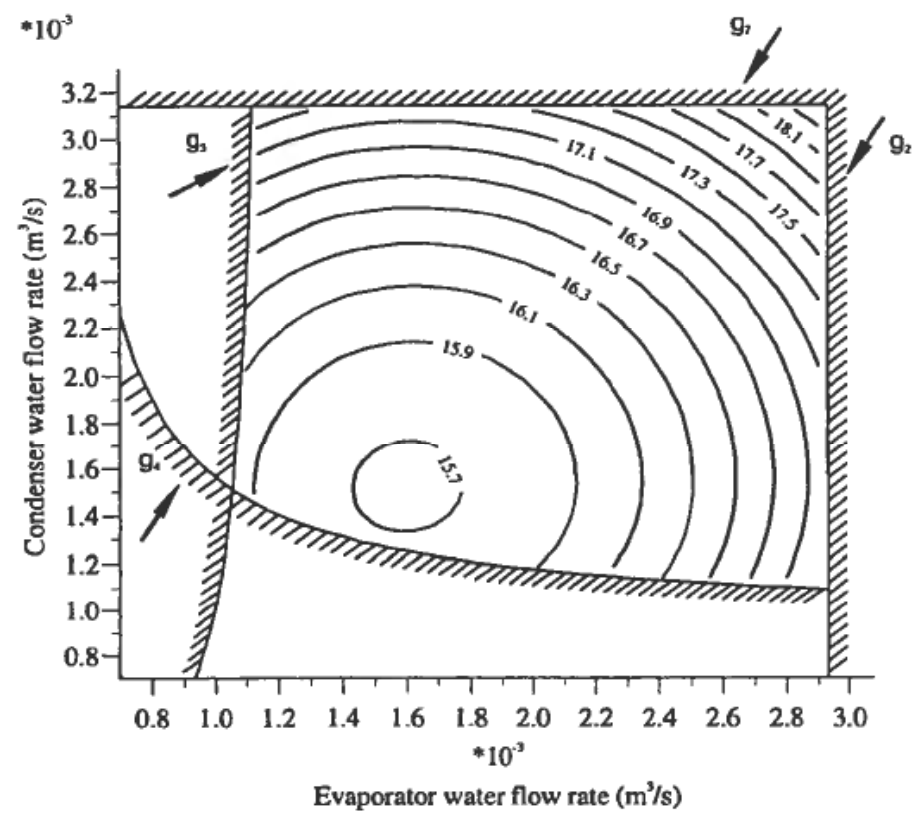

Figure 4. Contour and constraint diagram for the heat pump unit steady-state optimization problem, Case I 


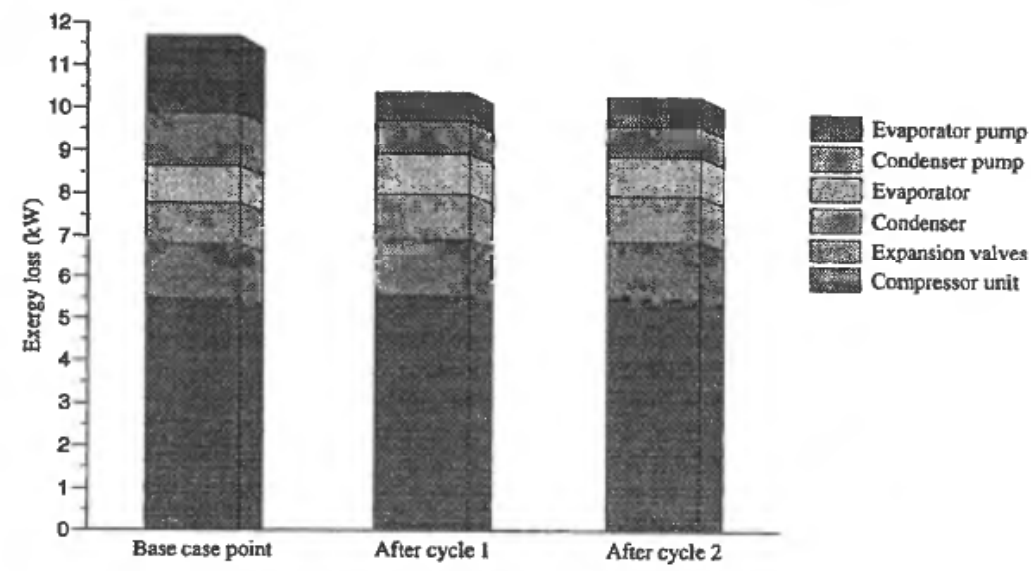

Figure 5. The distribution of the various exergy losses in the heat pump unit. Case II.

\section{Case II}

In this case study the heat pump unit was moved to a new operating point. The evaporator water inlet temperature was $5 \cdot 5^{\circ} \mathrm{C}$, and the condenser water inlet temperature was $46 \cdot 5^{\circ} \mathrm{C}$. The initial set-points for the temperature controller, and the evaporator and condenser flow controllers were set at $50.0^{\circ} \mathrm{C}, 3.0 \times 10^{-3} \mathrm{~m}^{3} / \mathrm{s}$, and $3.0 \times 10^{-3} \mathrm{~m}^{3} / \mathrm{s}$ respectively.

Table 7 shows the mean values of the measurements, the estimated parameters and the optimum independent variables during two optimization cycles. The calculated optimum set-points for the temperature controller, and the evaporator and condenser flow controller were $50.96^{\circ} \mathrm{C}, 2.10 \times 10^{-3} \mathrm{~m}^{3} / \mathrm{s}$, and $2.37 \times 10^{-3} \mathrm{~m}^{3} / \mathrm{s}$ respectively. The total electric power input to the heat pump unit decreased from $17.67 \mathrm{~kW}$ to $16.3 \mathrm{~kW}$.

The solution of the optimization problem was in this case study characterized by two active operational inequality constraints (underlined in Table 7). These constraints were the compressor discharge temperature high limit $\left(105.0^{\circ} \mathrm{C}\right)$, and the evaporator water outlet temperature low limit $\left(2 \cdot 0^{\circ} \mathrm{C}\right)$. Due to the accurate model prediction, the constraints are maintained within acceptable limits.

Figure 5 shows the distribution of the various exergy losses in the heat pump unit. The exergy losses in the water pumps decreased, but the reduction was limited by the two operational feasibility constraints becoming active. The heat pump unit exergetic efficiency increased from $\zeta_{e x}=0.378$ to $\zeta_{e x}=0.412$, i.e. an increase of $8.9 \%$, and the heat pump unit exergy losses decreased from 11.7 to $10.3 \mathrm{~kW}$. This case study demonstrated the flexibility of the optimizing control system. Even if operational inequality constraints became active, the control system was capable of maintaining the process operation feasible, and at the same time satisfying the load specification.

\section{Conclusions}

It is demonstrated that the multilayer approach of hierarchical control theory is useful in organizing the control structure synthesis problem, and that the multilayer control structure have the ability to predict optimum operating conditions for continuous processes designed for steady-state operation. It is further demonstrated that 


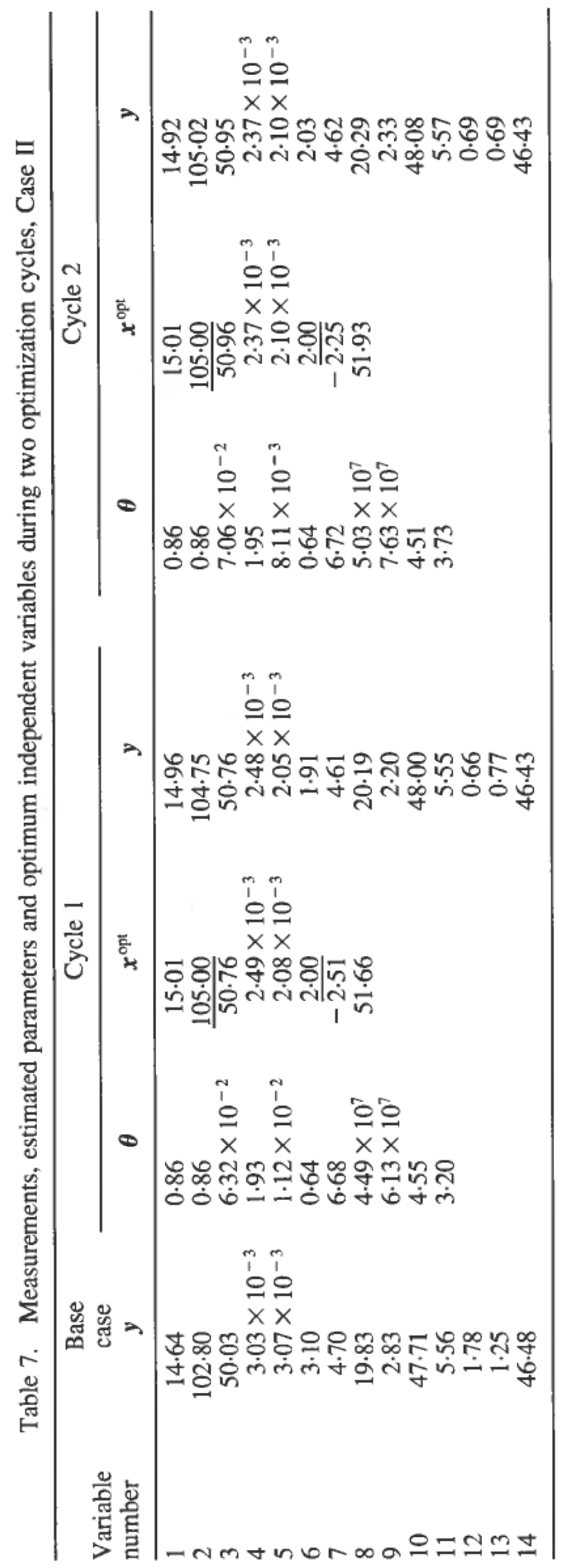


the "infeasible path" nonlinear programming approach is promising in solving the steady-state model-based optimizing control problem. In this approach the performance criterion, the algebraic model equations, and the operational feasibility constraints are solved simultaneously.

The experimental laboratory implementation demonstrated the effectiveness of the on-line model-based steady-state optimizing control scheme in finding the optimum operating conditions of the experimental heat pump unit. The scheme, which made use of a sequential quadratic programming algorithm, enabled convergence to the optimum in a small number of cycles. Both the computational efficiency and the robustness of the "infeasible path" nonlinear programming approach were demonstrated through the implementation.

The experimental case studies demonstrated further the ability of the model-based optimizing control scheme to predict accurately the heat pump performance and operational constraints. This was due to the rigorous adaptive heat pump unit model, which ensured that an operational feasible solution was calculated and implemented in the regulatory control system.

The steady-state identification approach was slow because one must wait for the process to settle to a steady-state after each change in the set-points. This approach will not be sufficient if the process is subjected to persistent disturbances which prevent it from reaching a steady-state operating point.

\section{REFERENCES}

[1] ARKun, Y. and Stephanopoulos, G. (1980). Optimizing Control of Industrial Chemical Processes: State of the Art Review. Proc. Joint Autom. Control. Conf., 1, WP5-A.

[2] Braun, J. E., Klein, S. A., Beckman, W. A. and Mitchell, J. W. (1989). Methodologies for Optimal Control of Chilled Water Systems Without Storage. ASHRAE Transactions, 95.

[3] CHO, C. H. and NORDEN, N. (1982). Computer Optimization of Refrigeration Systems in a Textile Plant: A Case History. Automatica, 18.

[4] Edgar, T. F., and Himmelblau, D. M. (1989). Optimization of Chemical Processes. McGraw-Hill.

[5] Galloway, J. E. and GoldschmidT, V. W. (1991). Relationship between Refrigerant Charge, Capacity, and Efficiency of a Static Heat Pump. Proceedings of the XVIIIth International Congress of Refrigeration, Montreal, Quebec, Canada, August 10-17.

[6] JaCkson, P. J. and AGNEw, J. B. (1980). A Model-Based Scheme for the On-Line Optimization of a Liquid Extraction Process. Computers and Chemical Engineering, 4.

[7] KAYA, A. and SOMmER, A. (1985). Energy Management of Chillers by Multilevel Control and Optimization. Transactions of the ASME, 107.

[8] Latour, P. R. (1979). Use of Steady-State Optimization for Computer Control in the Process Industries. Proceedings of the Fifth Annual Advanced Control Conference.

[9] LefKowITZ, I. (1966). Multilevel Approach Applied to Control System Design. Transactions of the ASME, June.

[10] MacARTHUR, J. W. and Grald, E. W. (1988). Optimal Comfort Control for Variable-speed Heat Pumps. ASHRAE Transactions, 94.

[11] Morari, M., Arkun, A. and Stephanopoulos, G. (1980). Studies in the Synthesis of Control Structures for Chemical Processes. AIChE Journal, 26.

[12] SchitTKOWSKI, K. (1985). NLPQL: A Fortran Subroutine Solving Constrained Nonlinear Programming Problems. Annals of Operations Research, 5.

[13] Tassou, S. A. and AL-Nizari, H. O. (1993). Investigation of the Effects of thermostatic and Electronic Expansion Valves on the Steady-State and Transient Performance of Commercial Chillers. International Journal Refrigeration, 16.

[14] ZimMER, H. (1976). Chiller Control Using On-Line Allocation for Energy Conservation, 1976 ISA Annual Conference, Houston. 


\section{Nomenclature}

A Area, $\mathrm{m}^{2}$

$c_{\mathrm{p}} \quad$ Constant-pressure specific heat, $\mathrm{kJ} /\left(\mathrm{kg}^{\circ} \mathrm{C}\right)$

E Exergy, kW

g Inequality constraint vector

$h \quad$ Specific enthalpy, $\mathrm{kJ} / \mathrm{kg}$

$\boldsymbol{h} \quad$ Equality constraint vector

$k_{\alpha} \quad \alpha$-confidence level in the distribution of range

$\boldsymbol{k} \quad$ Vector of constants

$\dot{P} \quad$ Electrical power input, kW

$p \quad$ Pressure, bar

$T$ Temperature, ${ }^{\circ} \mathrm{C}$

$\mathscr{T}$ Temperature, $\mathbf{K}$

$\Delta T$ Temperature difference, ${ }^{\circ} \mathrm{C}$

$\boldsymbol{u}$ Manipulated variable vector

$\dot{V} \quad$ Volume flow rate, $\mathrm{m}^{3} / \mathrm{s}$

$v$ Disturbance vector

$\boldsymbol{v}_{1} \quad$ Slow disturbance vector

$v_{2} \quad$ Fast disturbance vector

$\boldsymbol{x}$ State variable vector

$\boldsymbol{y}$ Measurement vector

\section{Greek Letters}

$\theta \quad$ Parameter vector

$\sigma \quad$ Measurement error standard deviation

$\Phi \quad$ Performance criterion

$\rho \quad$ Density, $\mathrm{kg} / \mathrm{m}^{3}$

$\zeta \quad$ Efficiency

Subscripts

com Compressor

c Condenser

dis Discharge

e Evaporator

ex Exergetic

hp Heat pump

in Inlet

is Isentropic

liq Liquid

out Outlet

pc Pump condenser

pe Pump evaporator

ref Reference

sc Secondary condenser

se Secondary evaporator

suc Suction 
Superscripts

opt Optimum

sat Saturation

Estimated or predicted

Mean value 